\title{
Navigating Alarming Media Messages About Nutrition and Health
}

\section{How Students Engage in Critical Examination of Science in News Media}

\author{
Jonna Wiblom ${ }^{1} \cdot$ Maria Andrée ${ }^{1} \cdot$ Carl-Johan Rundgren ${ }^{1}$ (iD
}

Published online: 8 January 2020

(C) The Author(s) 2020

\begin{abstract}
This study focuses the emerging need for young people to critically respond to alarming messages in contemporary media highlighting the potential benefits or harms of certain foods. Besides being technical, advancements in the field of nutrition reported in media are often of tentative and speculative character, primarily selected and constructed on the basis of their news value rather than as representing established knowledge. The study aims to study students' capabilities to navigate and critically respond to controversial media messages about health and nutrition in the context of science education. Our theoretical point of departure is in the concept "an examined life" in the critical reflection tradition of Socrates and the Stoics. We analyze how groups of upper secondary science class students engage in critical examination of a controversial message about cow's milk encountered through Swedish public service news media on the Internet. The results illuminate that even when controversial findings are produced by a reputed university and communicated through independent media, students are capable of discerning the need to scrutinize such findings and are capable of performing such critical examination drawing on experiences of scientific investigations. Students' openness to question authoritative voices in society and to illuminate the new findings on milk from multiple perspectives reflects how "an examined life" may be enacted in the context of science education. Inviting students to participate in related activities shows promise for enabling a critical examination of themselves and others in ways deemed important for democratic citizenship.
\end{abstract}

Keywords Critical examination · Nutrition · Health · News media $\cdot$ Science education · "An examined life"

Carl-Johan Rundgren

carl-johan.rundgren@mnd.su.se

Jonna Wiblom

jonna.wiblom@mnd.su.se

Maria Andrée

maria.andree@mnd.su.se

Extended author information available on the last page of the article 


\section{Introduction}

As reflected in science education curricula around the world, developing students' capabilities to critically examine science is a prominent learning goal at all levels of education (McClune and Jarman 2014). In the field of science education research, critical examination of science is traditionally seen as part of the concept of scientific literacy and as such recognized as central for young people's active participation in society (c.f. Andreé and Lundegård 2013; DeBoer 2000; Laugksch 2000). As digital news media becomes an important arena for people's engagement with science, the arenas of relevance for developing scientific literacies in education also changes (Rundgren et al. 2012). An increased access to digital devices in schools, combined with the traditionally strong position of news media in science classrooms, undoubtedly makes science news on the Internet a relevant context for developing students' critical engagement with science (Klosterman et al. 2012).

Although today's societies are networked societies, we cannot assume that the Internet alone will educate people to critically examine controversial science in the media. On the contrary, we need to question earlier conceptions of younger generations as "digital natives," innately capable of sorting out the vast amount of scientific and nonscientific claims available in digital sources, of which news media is only one (Buckingham 2003). A significant part of the science reported in news media is sensationalist articles about nutrition and health containing alarmist headlines or contradictory information about what foods to eat or to avoid (Nagler 2014). Given the persuasiveness of mass media, providing students with opportunities to navigate the constant flow of alarming messages about health and nutrition on the Internet is central in a science education for citizenship (Bradford 2013). However, among scholars there is also ongoing discussion about what critically examining science in media actually entails (Chang Rundgren and Rundgren 2014).

The aim of this study is to develop the notion of students' capabilities to navigate and critically respond to controversial science in media in science education.

\section{Background}

\subsection{News Media in Science Education}

Over the past decades, the notion of citizenship education and its implications for curricula have been examined from multiple conceptual frameworks, such as " 21 st century skills" (c.f. Dede 2010; OECD 2005), "Bildung” (Sjöström, Frerichs, Zuin and Eilks 2017) and "the Sustainable Development Goals" (United Nations 2015). With a backdrop in the rapid technological changes and emerging global sustainability challenges, related frameworks commonly suggest critical engagement with complex societal issues as a key competence for participation in society. The Sustainable Development Goals (SDGs) point out health, nutrition, and responsible consumption and production of foods as interrelated areas where we face numerous global challenges, for instance, regarding obesity, malnutrition, diabetes, and the use of antibiotics. The SDGs further emphasize the important role of education in providing children and youth with learning opportunities that enable them to acquire the knowledge and capabilities needed to promote lifelong health and participation in vocational and professional life (United Nations 2015). 
Issues concerning nutrition, health, and food choices are recurring topics in contemporary news media and oftentimes comprises (but are by no means limited to) aspects of science and scientific research. Thus, developing students' capabilities to navigate and critically examine related issues in contemporary media is of particular interest in a science education for citizenship. While most science in news media is cutting-edge and under construction, much of the subject content in school science curricula comprises well-established science. Among scholars, there are suggestions that science education for critical citizenship ought to emphasize students' knowledge about how science is produced as well as the social construction of news media (c.f. Belova and Eilks 2016; Chang Rundgren and Rundgren 2014; Eilks et al. 2014; Stuckey et al. 2015). Of particular interest to this study, and in alignment with previous studies of news media in science education (c.f. Hodson 2011; Weinstein 2009), is the specification of the concept of scientific literacy to "critical scientific literacy" suggested by Priest (2016). From a citizen perspective on science education, she depicts that critical scientific literacy focuses on how lay people make sense of science in media, as well as how science journalists and other science communicators themselves make sense of science. Priest (2013 p. 141) argues that "The real reason to raise scientific literacy is to improve democracy - so that people can make good decisions, individually and collectively, on matters related to science and technology, which will require critical rather than factual science literacy." Chang Rundgren and Rundgren (2014) have conceptualized related educational approaches as "scientific media literacy," meaning that science education should invite students to learn through as well as about media (see also Buckingham 2003; McClune and Jarman 2012). Learning through media refers to the process of students learning science by accessing scientific information, for instance, as reported by science journalists on the Internet. To be able to understand and evaluate the scientific content in media, students need to be familiar with the scientific concepts, theories, or models referred to in related articles or posts. Learning about media points to the need for making students aware of how science in media is selected and constructed for various purposes - where representing established or common knowledge is not necessarily one such purpose. However, science education media have traditionally been used for purposes other than promoting students' critical engagement with controversial science. News media in particular have been used with the intention of demonstrating the impact and relevance of science in society, to contextualize scientific concepts, and to raise students' interest in science (Klosterman 2012).

The gradually increased emphasis on students" "media awareness" or "media savviness" in science education research is reflected in several contemporary studies focusing on the development of students' critical examination of science in media (Belova and Eilks 2016; Solli et al. 2017; Wiblom et al. 2017). When a panel of British science and English teachers, science journalists, science communicators, and media educators were interviewed about key aspects of critical examination relevant for science education, they highlighted knowledge across four interrelated domains: science knowledge, media awareness, literacy, and the habit of an enquiring mind (McClune and Jarman 2010). Media awareness is specified as students' understanding of journalistic practices, the nature of news, and the characteristics of newspaper reporting. In a later publication, the authors further stress that media awareness should not be regarded as a generic skill detached from the disciplines covered in news media. On the contrary, student media awareness should be developed in "the context of science reporting and with the manner in which such matters manifest themselves specifically in the context of the reporting of science" (2012 p. 7). With the introduction of digital devices and the Internet to classrooms and society at large, students' access to science is no longer limited to news 
media. When students search on the Internet for science-related information, they are faced with navigating and critically examining multiple sources of information that may provide different and conflicting views (Mason et al. 2018). This navigation become even more challenging when the debates concern complex global issues such as those relating to health, food consumption, and climate change (Solli et al. 2018). In an education for citizenship, there is an emerging need to continue unpacking the notion of students' media awareness in ways sensitive for the specific challenges and possibilities that emerges when science is confronted online.

It has been argued that science education for critical citizenship ought to focus on developing students' capacities "to weigh a number of incommensurate factors-hereunder value principles and scientific evidence" (Nielsen 2013 p. 381). Such a multi-perspective approach to critical examination of science has recently been addressed in a Swedish study about students' dialogic engagement with a controversy about hydraulic fracturing as presented on the Internet (Solli et al. 2017). In addition to scrutinizing the recurring scientific evidence about hydraulic fracturing, the students brought in their own, as well as other stakeholder, voices to examine multiple aspects of the issue. Solli and colleagues conclude that the process of engaging students in a dialogic examination of science presented on the Internet shows promise for developing their critical appraisal of the complexity that typically surrounds science in media. This closely aligns with another recent Swedish study performed in a similar context (Wiblom et al. 2017). The findings of the latter study suggest that when upper secondary school students collaborate to evaluate health information on the Internet, the trustworthiness of the science is negotiated in relation to the science education context, to the purposes constituted in classroom practices, and to what is personally relevant for the students.

\subsection{Science in News Media}

Beyond formal education, science in news media has long been an important means for individuals to participate in scientific advancements (McClune and Jarman 2014). Following the development of new communication technologies, the increased use of digital devices has changed the way lay people gain access to science in news media. The Internet has become the dominant medium through which we take part in and share information in all areas and disciplines, including science (Hodson 2011). This is confirmed in a biannual survey based on 5000 Swedish youths' self-reported media habits (the Swedish Media Council 2019). The latest survey shows that $83 \%$ of the 17-18-year-olds take part of news and that $89 \%$ of the news media consumers in that age span relies on digital devices such as mobile phones to access news. An earlier US survey with the particular focus on science news consumption indicates that even though the majority of people use a mix of traditional print-based media and online sources to access science-related news, younger generations are more prone to rely solely on news reported through online media ( $\mathrm{Su}$ et al. 2015).

Through a somewhat utopian lens, a recurring suggestion is that the Internet opens up spaces for democratic citizenship and the individual's self-management in lifestyle-related issues (Choi et al. 2017). Although the Internet unquestionably provides access to an unprecedented amount of science-related information, parts of which are filtered through science journalism, a concern is that the vast amount of information on the Internet is challenging to navigate (Flaxman et al. 2016). For instance, the science and technology research disseminated through media may be technical and, as such, difficult for someone without specialist 
competences to understand and put under a critical lens (Lee et al. 2014). In fact, the quality of scientific research and associated claims may sometimes be just as challenging for science journalists to assess and convey to a public audience (Priest 2013). In addition to the science reported by journalists, searchable scientific databases like Google Scholar provide lay people with an unprecedented access to some of the peer-reviewed science literature published online (although much work is still not available in its complete form through open access). Yet, for lay people to inform themselves with peer-reviewed science literature, they need to overcome a range of obstacles such as knowing where to find it, how to read it, understanding the vocabulary, and to some extent being familiar with the scientific process in order to validate or evaluate the scope of the study (Gillen 2006). Thus, scholars have concluded that the increased access to scientific primary literature on the Internet may not be so easily accessed after all (Berzonsky and Richardson 2008).

Besides being technical, the scientific advancements reported in the news are often of a tentative and speculative character, primarily selected and constructed on the basis of their news value rather than as representing established knowledge (McClune and Jarman 2014; Priest 2013). This is not least reflected in the nutrition coverage and health messages published in the news (Kininmonth et al. 2017). In this study, our starting point is the emerging need for young people to critically respond to alarming headlines in contemporary media highlighting the potential benefits or harms of certain foods, drinks, or supplements. There has long been a concern that conflicting media messages about nutrition may lead to public confusion about what foods are healthy to eat and the belief that nutritionists disagree or keep changing their minds (c.f. Nagler 2014). Yet as pointed out by Nagler (2014), contradictory findings about nutrition may be due to differences in study designs, how nutritional intake is measured, or what cohorts are followed. Also, like any other research field, nutrition research is evolutionary, and seemingly conflicting findings ought to be negotiated and reconciled in relation to the accumulated knowledge in that specific field (Goldberg and Silwa 2011). A recent study by Lee, Nagler, and Wang (2018) indicates that mixed media messages about nutrition encountered on the Internet or in newspapers may facilitate people's critical engagement with science. However, Lee and colleagues also point out that critical engagement with nutrition information in the media is conditioned by how people understand scientific research and their capabilities to make sense out of conflicting findings or advice.

As pointed out by McClune and Jarman (2014 p. 11), "[s]cience journalism, no matter how good it is, may not in itself promote science literacy but is a valuable resource in achieving this goal." Thus, when addressed purposefully in science education, alarming media messages about health and nutrition may potentially enable young people's present and future participation in democratic societies.

\section{Theoretical Point of Departure}

In this study, we draw on the concept of "an examined life" in the critical reflection tradition of Socrates and the Stoics. Our understanding of the concept builds on how it has been developed in the philosopher Martha Nussbaum's (1997) work in framing the core values of an education for critical citizenship. Similar to, e.g., the SDGs (United Nations 2015), Nussbaum's framework "the Capabilities Approach" (Nussbaum 2011) is concerned with the human right to develop the capabilities needed to participate fully in society and to fulfill her potential in dignity and equality. Furthermore, Nussbaum's framework offers a normative account of the 
capabilities fundamental for all citizens to develop. With reference to Aristotle's ethics, Nussbaum (2011 pp. 33-34) suggests a list of ten capabilities that she considers central to human flourishing, including bodily health, practical reason, and affiliation. Practical reason is depicted as making balanced decisions through dialogic reflection, whereas affiliation involves to engage in social interactions and to show compassion and concern for other human beings. With an emphasis on students' capabilities to practical reason and affiliation, her vision for an education for citizenship is one that "[d]raws citizens toward one another by complex mutual understanding and individual self-scrutiny, building a democratic culture that is truly deliberative and reflective, rather than simply the collision of unexamined preferences" (Nussbaum 1997 p. 294). The way in which Nussbaum's framework provide pointers about what capabilities to value (and for what reasons) has previously been suggested as useful in reconsidering the aims of a science education for citizenship (Cockerill 2014).

Nussbaum's (1997) conceptualization of "an examined life" focuses on our capabilities to discern and willingness to doubt ourselves and how we live. She suggests that a critical examination of issues that concern our daily lives has the potential for creating people who "think for themselves rather than simply referring to authority, who can reason together about their choices rather than just trading claims and counter-claims" (Nussbaum 1997 p. 19). Becoming aware of and reasoning about one's cultural identity, values, beliefs, habits, and positions mean to critically examine the arguments used to justify it and to imagine multiple possible ways of living. When we are able to discern a position, we have the capacity to distinguish it as divergent from one or several alternative positions. Contrasting what is new with what is already familiar expands our repertoire of possible positions and enables us to become aware of and reconsider our own. With the Socratic ideal of "an examined life" come the capabilities to reason through complex issues and to understand and evaluate one's own thinking and that of others (and the implications) and a willingness to renegotiate the views one held in the beginning of the inquiry. Such an inquiry involves knowing the difference between logically valid and invalid arguments, as well as to being able to say something about the truth of premises.

The curricular implications are that an education for citizenship ought to provide students with opportunities to face controversial issues and question the taken-for-granted, natural, or neutral (Nussbaum 1997 p. 32). Students should be invited to "sort out what they think they know, to test beliefs for consistency, inferences for validity, noticing if the beliefs they carry and share are inconsistent" (op. cit. p. 36). Nussbaum argues that "[i]nstead of learning logical analysis in a vacuum, students now [in such educational practice] learn to dissect the arguments they find in newspapers, to argue about current controversies in medicine, law and sports, to think critically about the foundations of their political and religious views" (op. cit. p. 18).

\section{Research Questions}

By drawing on the framework of "an examined life," this study focuses specifically on students' capabilities to navigate and critically respond to alarming news concerning health and nutrition in digital media. The research questions are:

- What do upper secondary school students discern as relevant foci for critical examination of alarming findings on nutrition and health encountered in news media on the Internet? 
- How may encounters with alarming news on nutrition and health enable students' engagement in critical examination in line with the framework of "an examined life" (including the questioning of one's own and others' views and habits and a willingness to renegotiate views and habits)?

\section{Study Setting}

The study was conducted over 1 year in a collaboration between two researchers (author 1 and author 2) and five experienced science study teachers in upper secondary school. The teachers were recruited from five Swedish schools varying with respect to program specializations as well as geographic and socioeconomic spread. One hundred and thirty upper secondary school students, attending a vocational or study preparation program at either of the five schools participated as part of ordinary science study class (Naturkunskap in Swedish). All participants gave informed consent to participate.

The overarching purpose of the research collaboration was to develop new teaching, learning, and assessment practices concerning critical scrutiny of science-related issues on the Internet in science study class. In Swedish science studies, it is stated that " $[\mathrm{t}]$ eaching of science studies should aim at helping students develop their knowledge of science, and the capabilities to critically evaluate and develop their views on issues with a scientific content" (The Swedish National Agency for Education 2011). This aim is specified in several subjectspecific learning objectives, including that students should acquire "knowledge of the consequences of different lifestyles for both personal health, public health and the environment" and "knowledge of how science is organised and how it can be critically examined and used for critical examination." Since the teachers and the researchers commonly identified the abovementioned learning objectives as particularly challenging to address in class, they were chosen as the main focus for the research collaboration. This study builds on specific episodes where the students discussed a controversial Swedish nutrition study which the students had accessed through public service news media on the Internet.

\subsection{The Student Task}

To target the abovementioned learning objectives, the teacher-researcher team jointly designed, implemented, and evaluated a teaching sequence. The sequence was implemented during two 80 -min lessons by each teacher, respectively, as part of their ordinary science study classes. The teaching sequence included:

- Lesson 1: During the first lesson, the teachers informed the students about the learning objectives and introduced a preparatory task for the second lesson that followed. The preparatory task engaged the students in a joint critical examination of news articles about meat consumption. The articles were selected beforehand by the research team in order to highlight different perspectives (such as economy, health, ethics), positions, and/or actions related to meat consumption and vegetarianism. In addition to the articles, the students were provided with a mnemonic device "Who says What and Why?" to support and structure their critical evaluation. The students were divided into groups of 3-6 and instructed to read, summarize, and critically examine the articles guided by the selfquestioning analytical routine. The group discussions were wrapped up in a whole-class 
exercise of listing and categorizing the identified perspectives and arguments about meat consumption on the whiteboard.

- Lesson 2: During the second lesson, the students were given the task of scrutinizing an ongoing controversy between a cow's milk and an oat milk producer in Sweden. Similar to, for example, almond or soy milk, oat milk is a plant-based substitute made of grounded oats mixed with water and food excipients. It is promoted as a healthy and environmentally friendly cow's milk substitute and has become increasingly popular among Swedish consumers. The controversy between the two producers had created great media attention at the time and raised questions about sustainable lifestyle choices. The controversy was introduced via a 15-min news report from public service radio, followed by oral and written instructions:

A. Individual task: Use the Internet to find information about oat and cow's milk production and consumption. Pay particular attention to information relating to environment and health. Use the mnemonic device "Who says What and Why?" to critically examine your sources.

B. Group task: In groups of 3-6, map and evaluate the information, arguments, and opinions about oat and cow's milk identified in the individual search online. Wrap up the group discussion by sharing and justifying your personal point of view (voluntary). This part of the discussion aims to provide you with multiple possible ways of reasoning about the issue. ${ }^{1}$

\subsubsection{A Controversial Nutrition Study in Swedish News Media}

The initial screening of the data revealed that students in all groups had come across a specific news article available through Swedish public service news media during their individual Internet searches (SVT 2014-16-03). The news article reported on a controversial Swedish nutrition study about milk consumption that had recently been published in the British Medical Journal (Michaëlsson et al. 2014). The news article about the study was headlined "Swedish study: Milk consumption is associated with increased mortality" (our translation, SVT 201416-03) and had high rankings on Google's hit list at the time.

The media attention and debate that followed the publication of the nutrition study can be seen as reflecting the cultural-historical position of cow's milk in Scandinavia. Milk is valueladen in Sweden and has a reputation for being old-fashioned, natural, healthy, fast, and light (Jönsson 2005). The milk-health connection can be traced back to Swedish Milk Propaganda (in Swedish Mjölkpropagandan, an association formed in 1923 and financed by the Swedish government and milk producers) that successfully branded cow's milk as a healthstrengthening beverage, especially for growing children and sick people (Mjölkpropagandan 1933-1964). Cow's milk is commonly served with lunch in Swedish schools; however, during the last few decades, the image of cow's milk as a healthy and sustainable choice of beverage has been challenged. Both the production and the consumption of milk in Sweden are declining, partly replaced by an increased consumption of vegan and lactose-free plant-based

\footnotetext{
${ }^{1}$ The group discussions were followed by an individually written short paper about the issue. The written task is not a part of this study.
} 
substitutes such as nut, soy, and oat milk (The Swedish Agriculture Department 2018). Yet cow's milk production is still the highest-grossing agricultural sector in Sweden, and the national consumption of milk per capita significantly exceeds the European average (the Swedish Agriculture Department 2018).

As opposed to the common Swedish conception of cow's milk as a bone-strengthening and overall healthy choice of beverage, the news article referred to suggested a connection between the number of glasses of milk consumed daily and the risk for bone fractures and death by cardiovascular diseases in women and men (SVT 2014-16-03). The readers were informed that the study was based on food frequency questionnaires that had been distributed among 61,000 Swedish women and 45,000 Swedish men in order to map their average frequency of consumption of 96 different foods, including cow's milk. One of the researchers behind the study who was interviewed for the article stated that "for each glass of milk that a woman consumed [sic], her risk of death increased by $15 \%$. For men the risk of death increased by $3 \%$. Also, hip joint fractures were $60 \%$ more common among women who consumed three glasses of milk or more each day compared to women who consumed less than one glass of milk each day" (SVT 2014-16-03, our translation). The researcher suggested that milk sugar (lactose) was linked to the mechanism that caused bone fracture risk and referred to earlier mice studies that have shown a correlation between galactose (one of the components in lactose) intake, oxidative stress, and inflammations. The researcher stated that:

Milk has been surrounded by an "air" of health. I am well aware that this is provocative. The study will not be received with open arms by all. But we have reasonable evidence behind our results. However, we do not want people to panic because of this. One cannot rely on a single study to give recommendations on a population level. (SVT 2014-16-03, our translation)

In the last part of the article, the interviewed researcher admitted:

I have drunk plenty of milk over the years. Two years ago, I switched to drinking yoghurt instead. For me personally, I think there is evidence enough for taking such a step. The downside of publishing this article is that it will affect the milk producers negatively. However, I think it is important that the facts become public. (SVT 2014-16-03, our translation)

The article also quoted a nutritionist employed by the Swedish milk producer association. She stressed that " $[\mathrm{t}]$ his is a single observation single study. It shows statistical correlations. Not cause and effect /.../ When it comes to nutrition studies, we need randomized studies in which people are divided into different control groups" (SVT 2014-16-03, our translation). At the end of the article, a link to the issue of the British Medical Journal, in which the nutrition study had been published, is provided, and the journal article of the study is available through open access (Michaëlsson et al. 2014).

\section{Data Collection and Analysis}

\subsection{Data}

The empirical data consists of the video recordings from 10 student group discussions during the second lesson (as described in the study setting session). The video-recorded groups were informally selected in that one, or a couple of groups in each class volunteered. The voluntary 
nature of participation was important to ensure the integrity and voices of the students throughout the intervention. That groups volunteered may, however, have as consequence that the participating groups may be more outspoken and less insecure concerning participation in the tasks of scrutinizing science in the media. In order to afford variation in the collected data concerning student reasoning, the schools participating in the study were selected to represent a spread with regard to school program (vocationally oriented and theoretically oriented), school form (public school and charter school), as well as socioeconomic spread. Designbased research typically shares an interest in generating knowledge about an intervention and/ or through an intervention (McKenney and Reeves 2012). In line with the latter research interest, the intervention in the form of a student task was here used as a context for studying how the students collectively engaged in critical examination of science encountered on the Internet. When conducting educational design-based research, it is necessary to ensure information richness without being overwhelmed of data (McKenney and Reeves 2012).

In addition to the teacher, the first author was present for data collection in all classes during the second lesson. Each recorded group discussion lasted approximately $30 \mathrm{~min}$ and was transcribed verbatim by the first author. The article about the nutrition study was brought up for discussion in all groups. All episodes where the nutrition study was discussed were selected for the analysis in this article (in total 42 episodes, each ranging from 0:30 to 4:45 min).

\subsection{Qualitative Content Analysis}

In the present study, we adopted qualitative content analysis as described by Graneheim and Lundman (2003) and Graneheim et al. (2017) to frame how the students engaged in critical examination of the alarming findings on milk. As will be described in the following, our application of the framework included the following steps: 1) discern meaning units, 2) condense codes, 3) condense categories, and 4) formulate themes across students' discussions.

\subsubsection{Codes and Categories}

To get an initial sense of how students' conversations unfolded, we read through the transcripts a few times. Table 1 below illustrates how the qualitative content analysis framework was applied (Graneheim and Lundman 2003). In column 1, three meaning units have been coded and condensed into two categories relating to the same theme. Column 1 exemplifies three of the meaning units that were extracted from the transcripts. Meaning units were defined as all episodes during which the students discussed the public service article about the Swedish nutrition study. The remaining episodes, such as when the students discussed other sources or agreed on how to proceed with the task, were temporarily excluded from analysis. In the following step, the meaning units were condensed into codes. The coded meaning units served as labels for areas of content in students' critical examination of the alarming findings. For example, column 2 in Table 1 illustrates how the three meaning units have been condensed into codes labeled as: "The amount of milk and associated risks," "Too much is almost never good," and "Excess calcium." When all meaning units had been labeled with a code, the codes were grouped into categories of similar content. In the present study, each category served as an umbrella for content addressed in students' critical examination that in some way could be related to one another. As seen in column 3 in Table 1, the codes "The amount of milk and associated risks" and "Too much is never good" have both been associated with student 
discussions about the correlation between the amount of milk consumed and health effects and as such sorted under the category "Dose-response relationship."

\subsubsection{Descriptive Themes and Themes of Meaning}

The final step of analysis involved discerning themes in students' discussions. During thematization, the transcripts were read again as an entity to search for patterns across the data set as a whole. Graneheim, Lindman, and Lundman (2017 p. 33) distinguish between descriptive themes and themes of meaning. The former comprises "explicit expressions of what participants talk about." Our search for descriptive patterns in the material followed the trajectory of what became the foci of students' critical examination as they encountered the alarming new findings on milk. Column 4 in Table 1 illustrates that one of the descriptive themes in students' conversations concerned how science is produced and explained. During those episodes, the students were able to identify and use quality markers commonly applied to evaluate nutrition research, such as the study design and the dose-response relationship, to inquire into the claims made in the study on milk.

Complementary to the descriptive themes are the themes of meaning which "illuminate[s] a comprehensive interpretation of data" (Graneheim and Lundman 2017, p. 33). Even though all analytic stages previously described build on the researchers' subjective understanding of the material, discerning themes of meaning usually requires a higher degree of interpretation. In the present study, we used the framework of "an examined life" (Nussbaum 1997) as a conceptual tool to capture themes of meaning in how the students responded critically to the alarming findings on milk. The concept allowed us to interpret traits in students' conversations as qualitative expressions of critical examination of science in media. Thus, the theoretical point of departure enabled an understanding of students' critical responses to science in media as conditioned by their capabilities to question and renegotiate their own and others' views and habits. For instance, the concept "an examined life" enabled us to illuminate qualities in students' critical engagement with the new findings that relate to how they questioned authorities in society.

Table 1 Illustration of the qualitative content analysis

\begin{tabular}{|c|c|c|c|}
\hline 1. Meaning unit & 2. Code & 3. Category & 4. Theme \\
\hline $\begin{array}{l}\text { Student } 1: \text { Hm... they saw a } \\
\text { connection between the } \\
\text { number of glasses of milk ... } \\
\text { that it wasn't just that they } \\
\text { drank milk, but that a lot of } \\
\text { milk causes risk for this. But } \\
\text { a little milk... and it wasn't } \\
\text { that harmful at all }\end{array}$ & $\begin{array}{l}\text { The amount of milk and } \\
\text { associated risks }\end{array}$ & $\begin{array}{l}\text { The dose-response } \\
\text { relationship }\end{array}$ & $\begin{array}{l}\text { How is science } \\
\text { produced and } \\
\text { explained? }\end{array}$ \\
\hline $\begin{array}{l}\text { Student 1: You could question } \\
\text { that A LOT, I mean a big } \\
\text { quantity, and a lot is almost } \\
\text { never good }\end{array}$ & Too much is never good & & \\
\hline $\begin{array}{l}\text { Student 1: But it's the excess } \\
\text { of calcium... }\end{array}$ & Excess calcium & $\begin{array}{l}\text { The physiological } \\
\text { mechanism }\end{array}$ & \\
\hline \multicolumn{4}{|l|}{ Student 2: Yeah exactly. } \\
\hline $\begin{array}{l}\text { Student } 1: \ldots \text { that causes } \\
\text { osteoporosis }\end{array}$ & & & \\
\hline
\end{tabular}




\section{Results}

In the following section, the results of the qualitative content analysis are presented in two parts, each part addressing one of the two research questions, respectively. The first part provides an account of what the students discerned as relevant foci for critical examination of the alarming findings on milk presented in public service media. This part includes the descriptive themes focusing on student examination of (a) How is science produced and explained? (b) How is science communicated in media? and (c) What may be the consequences of new scientific knowledge? The second part provides an account of themes of meaning regarding how the students engaged in a critical examination in line with the framework of "an examined life" by (a) Questioning authorities and (b) Acknowledging multiple perspectives.

\subsection{Descriptive Themes-Foci of Students' Critical Examination}

The students' encounters with the alarming findings on milk enabled a critical examination of (A) How science is produced and explained, (B) How science is communicated in media, and (C) What the consequences of new scientific knowledge may be. In the following, expressions of each descriptive theme are exemplified with excerpts from students' conversations.

\subsubsection{A) How Is Science Produced and Explained?}

The first descriptive theme illustrates how the alarming new findings about milk enabled students' critical examination of how the scientific claims made in the nutrition study (as they were reported in the public service article) had been produced and explained. While engaged in such work, the students examined a range of established quality markers commonly applied to evaluate epidemiological correlation studies, such as how the results had been produced, validated, and explained. As they identified the need for further research, the students also acknowledged the research findings as part of a larger knowledge-building exercise about the health properties of milk and related issues which are important to examine in relation to the accumulated knowledge in that specific field of nutrition research. Thus, this theme provides an example of how the students, in their roles as nonscientists, were able to engage critically with science in ways that align with how related research claims are scrutinized from within science communities. Their capabilities to critically examine the scientific claims were conditioned by how they accessed and interpreted the methodological information and quantitative data about the nutrition study as presented in the public service article. However, their involvement in such work was in turn conditioned by the perceived necessity of questioning the university's authority to produce credible nutritional knowledge. We describe below how students' critical examination of the scientific claims encompassed dimensions of questioning the nutrition study design, the dose-response relationship, and the physiological mechanism.

The Study Design Excerpt A, below, illustrates how the alarming new findings about milk enabled Lee, Kim, and Nova to question how the nutrition study had been carried out. Whereas Lee and Kim revealed that they had come across the public service article during their Internet searches, Nova had not and asked Kim and Lee for more information about it. 
Excerpt A How long did the study run for?

1. Kim: About this osteoporosis study, it's based on a study from Uppsala University; so therefore, it is really well-grounded.

2. Nova: Really, how many people died?

3. Kim: There were ten thousand participants in the study, right?

4. Lee: Yeah, ten thousand that died... it was sixty-one [thousand] that [participated].

5. Nova: And that's because of milk or...?

6. Kim: They compared with how much milk they drank... compared with their death.

7. Lee: Ten thousand.

8. Nova: The consumption of milk, really?

9. Lee: I mean sixty-one thousand joined; ten thousand are deceased; five hundred had fractures.

10. Nova: For how long?

11. Lee: You mean...?

12. Nova: How long did the study run for?

13. Lee: Ehm... twenty years?

14. Kim: That's quite a lot.

15. Nova: What age were they?

16. Kim: I thought it would be, like, much longer; like, fifty years.

17. Nova: But what age were they?

18. Lee: Ehm... they were, like... it was women and men who were, like, forty-five-ish I think.

19. Nova: OK.

By emphasizing that the nutrition study was produced at a reputable Swedish university, Kim took expert knowledge at face value (1). Nova however wanted to know more about the study and started to ask for details regarding how the study had been carried out. Her questions that followed corresponded with some of the established measures for examining validity and reliability in large-scale correlation studies. Regarding validity, she considered cause and effect by first asking about the number of deceased and then questioned if "that's because of milk... or?" $(2,5,8)$. In asking about the duration of the study $(10,12)$, and the age span of the cohorts $(15,17)$, she also addressed the reliability of the nutrition study. Lee answered Nova's questions about the study design by reproducing a great deal of the detailed numerical data about the study that was presented in the public service article $(4,7,9,13,18) .{ }^{2}$ Kim attempted to make meaning of the numerical data provided by Lee, although he expressed ambivalence regarding how to evaluate the duration of the study. He first considered 20 years to be "quite a lot" of time to follow a cohort (14) but then immediately added that he actually expected it to be longer, "like fifty years" (16).

The Dose-Response Relationship The following Excerpt B illustrates how Semhar, Lollo, and Niat examined the dose-response relationship presented in the article - that is, the correlation between the amount of milk consumed and the presumed increased risk for bone fractures and premature death.

Excerpt B If you drink a whole lot

20. Semhar: A study made at Uppsala kliniska forskningscentrum [Uppsala Clinical Research Center] it is... it proves that $a$ lot of milk drinking increases the risk for bone fractures. I mean if you drink a whole lot.

21. Lollo: But I mean, that depends on... I mean how much do we think?

22. Semhar: I don't know.

23. Semhar: Kind of, that you drink it all the time, like, instead of water.

24. Lollo: Yeah, but all the time? Like a glass per day or...?

25. Semhar: Yeah, but if you drink milk with every meal, like, I don't know how much you drink but...

26. Niat: That depends from person to person too. How much you drink.

27. Niat: You should have looked up how much it was.

28. Semhar: Yeah. Maybe I should have.

\footnotetext{
${ }^{2}$ In the public service article, it was stated that "[ $\left.\mathrm{t}\right]$ he researchers followed 61.000 women and 45.000 men /.../ After just over 20 years, a quarter of the women were deceased, and 17.000 had had some sort of [bone] fracture. Among the men, who were followed up eleven years after the first survey, 10.000 were deceased and 5000 had had a [bone] fracture" (SVT 2014, our translation).
} 
Semhar assigned high probative value to university-based research as she stated that the nutrition study "proves" a correlation between high milk consumption and an increased risk for bone fractures (20). She particularly emphasized the large amount of milk needed to trigger the suggested increased risk for bone fractures and premature death (20). In doing so, Semhar pointed out the importance of considering the dose-response relationship in nutrition research. Her utterance on the amount of milk (20) enabled Lollo to further examine the doses actually studied $(21,24)$. The answers provided by Semhar, "a whole lot" (20) and "that you drink it all the time" (25), reflect how the studied doses were referred to in the beginning of the public service article, namely, as "high milk intake" and "larger amounts of milk" (SVT 2014, our translation,). Despite the lack of more precise information about the studied doses, Semhar, Niat, and Lollo probed various interpretations of the meaning of "a lot of milk" by measuring milk intake per glass (24) and by referring to the common ways of consuming milk in Swedish society - as a thirst-quenching alternative to water (23) and as a beverage to accompany a meal (25). Semhar and Niat wrapped up their discussion about the public service article by reinforcing the importance of considering the dose-response relationship $(27,28)$.

In the above conversation, the three peers recognized the studied doses as an important factor to consider when assessing the validity of nutritional correlation studies. The students were thus able to see beyond and nuance the alarming headline of the public service article that associated milk consumption with death.

The Physiological Mechanism The students' critical examination of the scientific claims made in the nutrition study also touched upon ways of understanding the physiological mechanism that makes milk unhealthy, as put forward in the article. Excerpt $\mathrm{C}$, below, illustrates how a group of students discussed the potential role of calcium in causing bone fractures.

Excerpt C It's the excess calcium

29. Eva: Ehm... connections between bone fractures and higher consumption of milk ...?

30. Max: But is it the excess of calcium... that causes osteoporosis?

31. Frank: Yeah, exactly.

32. Ted: One of the biggest advantages with ordinary milk... isn't it that it contains a lot of calcium which can decrease the risk for osteoporosis?

33. Frank: But despite the fact that calcium is good for the body it's been proven that... ehm... that it's not good in too large amounts.

34. Max: Yeah, it's like short term long term.

As Eva brought up the results of the nutrition study (29), she invited her peers to elaborate on possible ways to explain the contradictory findings about milk. Supported by Frank (31), Max suggested calcium as the nutritional component in milk that in excessive doses may have caused osteoporosis among the participants in the nutrition study (30). In the public service article about the nutrition study, it was stated that "the researchers believe that the mechanism that increases the risks [for bone fractures and premature death] relates to the lactose" (SVT 2014, our translation). However, calcium is never mentioned. In education and society generally, calcium is commonly associated with an increased bone density. Max's suggestion indicates that he used his previous knowledge about calcium as one of the nutrient components in milk in an attempt to make meaning of the new findings. Ted opposed Max's suggestion and pointed out that calcium is recognized to have the exact opposite effect, namely, to "decrease the risk for osteoporosis" (32). Like Semhar in Excerpt B (20), Frank confirmed his trust in research by stating that the new findings were "proven" (33). He then found a way to reconcile 
the contradictory knowledge claims about the role of calcium in milk by suggesting that "it's not good in too large amounts" (33). Max reinforced Frank's conclusion by adding that the time of exposure may also have influenced the results (34).

Two peers from another student group correctly referred to the physiological mechanism suggested in the article, namely, that "it had something to do with lactose." The public service article linked lactose to inflammation and oxidative stress, but the students associated lactose with food allergies saying that "[y]eah it's the lactose in milk ... I mean most people are, like, sensitive to lactose, and some people are more sensitive. Like, lactose intolerant." As pictured in Excerpt C, students' previous knowledge about milk complicated their attempts to probe or sort out the suggested physiological mechanism involved. Yet, despite the challenge to identify and understand the physiological mechanism described in the article, the students expressed curiosity and willingness to make meaning out of the puzzling scientific claims.

The Need for Further Research During their examination of the scientific claims, some students pointed out a need for further research in order to validate the results of the nutrition study. In the following Excerpt D, a group of students had come across another nutrition study that suggested a correlation between breast cancer and milk consumption. This opened up a space for the students to compare the breast cancer study with the study presented in the public service article.

Excerpt D It's based on the same study

35. Sam: But I definitely think that they should continue researching [the correlation] between

high milk intake and breast cancer. And, like, those animal testings, to see if it's really true. Can we be completely sure about that? And also, like, research about what nutrients... I mean what happens in the body when a person drinks a lot of oat milk. What will it actually lead to?

36. Tim: But really, what's going to happen?

37. Sara: But we don't know that!

38. Mimmi: Many of those disadvantages, they are actually based a lot on the same animal study.

39. Sam: Mm.

40. Mimmi: And I also believe, even this SVT article went on about that... ehm... it was someone then who was involved in milk production in some way and said, like... But we have to be critical to this one and not take this study too seriously yet.

41. Sara: No.

42. Mimmi: That's more like if this study starts to recur.

Sam questioned whether research based on animal testing could constitute foundations for conclusions about human responses to milk intake ${ }^{3}$ and recommended further research about the correlation between milk and breast cancer (35). In the same utterance, he also pointed to a lack of corresponding research about the nutrient components in oat milk, asking "what happens in the body when a person drinks a lot of oat milk?" (35). Sam's request for research on oat milk is particularly interesting in that the controversial media message about milk as unhealthy did not lead him into presumptive conclusions that oat milk (a common beverage substitute to cow's milk in Sweden) would then be a healthier option per se. Similarly, Sam demonstrated an awareness that the potential risks of consuming one item does not automatically imply that consumption of a substitute would be more beneficial. Tim expressed skepticism towards Sam's idea (36), while Sara also emphasized the importance of having more facts before drawing conclusions (37). Sam's recommendation for more research was reinforced by Mimmi, who said "many of those disadvantages, they are actually based a lot on the same animal study." She also acknowledged the importance of examining what constitutes

\footnotetext{
${ }^{3}$ The researcher who was interviewed in the public service article referred to the animal testing, suggesting that the galactose content in milk may cause "bodily changes" and "premature aging" in animals as well as in humans due to induced oxidative stress (SVT 2014, our translation).
} 
the foundation for reaching conclusions in research (38). In the utterances that followed, she suggested that one single study may not provide sufficient evidence and that scientific findings needed to "recur" in order to count as evidence $(40,42)$. The importance of interpreting one study in relation to the collected knowledge in the field was highlighted by the students in multiple groups, for instance, by Nova, who asked her peer Lee: "Did you find any study where one, like ... could benefit from milk?"

\subsubsection{B) How Is Science Communicated in Media?}

The second descriptive theme illustrates how the alarming new findings about milk enabled students' critical examination of how science in general and the nutrition study in particular are communicated in media. Recalling that the nutrition study was reported in public service news media, the students' critical examination was conditioned by their willingness to question the authority of science journalism and, by extension, a state-funded institution previously taken as "neutral." In doing so, they identified and discussed the importance of sources to reflect both sides of an issue, being transparent about primary sources, and being free from economic interests. The students pointed out that sources voicing multiple perspectives cannot be assumed to be objective or unbiased and that the interests or purposes of news media need to be distinguished from the interests or purposes of the people that they quote or interview. As described in the following, the students' critical examination of the public service media as communicator of science encompassed dimensions of elaborating on the notion of "objectivity" and how potential biases may influence how science is presented to a public audience.

Objectivity Excerpt E exemplifies how the new findings about milk as unhealthy created space for a group of students to re-evaluate their previous conception of certain sources as "objective."

Excerpt E Showing both sides

43. Sara: I think that Livsmedelsverket [the National Food Agency] or... If we somehow think about SVT or public service, don't you think that they have been involved in this? We were talking about this kind of milk culture earlier. Couldn't they have been involved in that stuff, and so one has to be a bit more critical towards them?

44. Sam: I mean... No!

45. Tim: So they should have moved away from that and are completely objective?

46. Sam: Yeah but they are completely objective, right? I mean they showed both sides.

47. Mimmi: Yeah. They show both sides.

Referring back to a previous discussion about milk as culturally laden in Sweden, Sara suggested that the National Food Agency and public service media may have contributed to promoting exaggerated health benefits of cow's milk (43). Sam, however, empathically opposed Sara's suggestion about public service media being involved in branding milk as healthy (44). The emerging dissensus regarding what sources to trust here functioned as an incentive for Sam to articulate his interpretation of objectivity, namely, to reflect both sides of an issue. He argued that since the public service article quoted one of the researchers behind the nutrition study as well as a representative of the Swedish milk producers, it was to be considered a "completely objective" source (46).

Even though Sara's skepticism toward reputed state-funded institutions in the Swedish society was not approved by the rest of the group, the controversial media message enabled her to question the trustworthiness of authorities and for her peers to give reasons for their judgments. 
Biases The trustworthiness of Swedish public service media as communicators of science was further elaborated on by two peers in another student group. The following episode (Excerpt F) illustrates how Selma and Malte discussed the meaning of "unbiased" sources.

Excerpt F Without self-interest

48. Selma: But otherwise I used, like, public service a lot. And such [media] that writes, like, without selfinterest. Because if you take companies or some health site that wants to sell books and such, then you'll see that it's the self-interest.

49. Selma: To know how to twist and turn the information. For instance, that they present a lot of disadvantages but no advantages. Therefore, I used sources like Livsmedelsverket [the National Food Agency] for instance.

50. Malte: What you have to consider though, if you say public service... If you think SVT [Swedish public service], that it's still often someone that they interview, so you have to consider who says what in the articles. I actually believe that it was someone from a milk organization that had commented on the article.

51. Selma: Yeah. But they presented their sources.

52. Malte: Yes, exactly.

53. Selma: So, they can still be unbiased.

54. Malte: Yes of course. SVT is still unbiased, but you can't assume that all the facts, or everything that is written in the article, doesn't derive from a person because it does. It's quotations.

During her conversation with Malte, Selma expressed trust in sources "without selfinterest," in this case Swedish public service media (SVT) and the National Food Agency (Livsmedelsverket). To illustrate her meaning of "self-interest," she contrasted nonprofit public service media with the economic interests of companies or health sites that "sell books and such" (48). By suggesting that sources with economic interests may present misleading or one-sided information, she provided an example of how selfinterest may affect the way science is communicated on the Internet (49). Malte problematized Selma's emphasis on economic interest by suggesting that public service still represents the voices of other people with potential biases (50). He exemplified his point by saying that "someone from a milk organization" (with an assumed interest in promoting milk) was interviewed in the public service article. Selma reinforced her perception of public service as trustworthy and "unbiased" by attending to another quality marker to evaluate trustworthiness, namely, transparency regarding primary sources $(51,53)$. In the utterance that followed, Malte distinguished the purposes of public service media from the purposes of the people they interview or write about. In doing so, he challenged Selma's assumption that nonprofit and transparent sources (like public service) communicate unbiased facts and produce media content that is free from human values or opinions. That may rather be exactly what is reflected- "[i]t's quotations!" he said (54). In his last utterance, Malte concluded that one has to consider "who says what" (50).

\subsubsection{C) What May Be the Consequences of New Scientific Knowledge?}

During their discussions, the students demonstrated awareness of the importance of examining scientific advancements in relation to the consequences for society and people's lives generally. Students' critical scrutiny of the controversial new findings was conditioned by their capacity to reflect upon the consequences of the new findings in ways responsive to societal and personal needs, as well as their willingness to question what may have shaped their own perception of milk. As described in the following, students' critical examination of the consequences of the new findings encompassed dimensions of culture and history and economy and marketing. 
Culture and History In some groups, the students acknowledged the special status of cow's milk in Sweden and discussed it as aligned with a national culture around food and historical events. In the episode that follows (Excerpt G), Elin and Vera started from a cultural-historical understanding of the importance of milk to Swedish society and probed the possible implications of milk consumption decreasing as a consequence of the nutrition study.

\footnotetext{
Excerpt G We're so dependent on milk

55. Elin: It was, like, that Swedes drink most milk, right?

56. Vera: Yeah, like, amongst the world's biggest in milk. But what should we do then to decrease our milk intake? How should we, like, replace... everything that we have in food for example?

57. Elin: But it's hard to replace because I think, like, since we're so dependent on milk...

58. Vera: Mm.

59. Elin: Yeah, like, in cooking. And in the U. S. they use cream but we use milk.

60. Elin: Me personally, I think that one should have milk and such. It will be difficult because we're so attached to milk now. If we were to cut down many people will... I think that a lot of people will oppose that and therefore that way won't work. So, they have to find..

61. Vera: If we think, like, about why we started to use milk, it was because, like, nothing grew. And then we had to turn to, like, the sources that we could get hold of for nutrition. And that's how we built, like, our entire food culture around milk.
}

In the conversation about the public service article, Vera and Elin discussed the consequences of the nutrition study from a Swedish perspective. Based on Elin's initial statement about Swedes as frequent milk consumers (55), Vera concluded that if Swedish milk consumption was to decrease (as was recommended in the public service article), Swedes would have to find substitutes for cooking (56). Elin too acknowledged the challenge of replacing milk, since the Swedish people "are so dependent on milk" (57). By comparing American and Swedish cooking traditions, she exemplified how different choices and use of dairy products can be culturally laden (59). Elin expressed a personal preference toward milk and demonstrated an awareness that acting in line with the findings in the nutrition study (decreasing the consumption of cow's milk) could be problematic in that it would stir up emotions and evoke people's resistance (60). In the last utterance of this conversation, Vera also illuminated food culture as historically conditioned, by pointing out that the high consumption of milk in Sweden may be due to past periods of crop failure and starvation (61).

Together, Elin and Vera probed a scenario in which the historical and cultural values of milk in Sweden might need to be secured as a consequence of the alarming new findings about milk. Relating the high milk consumption in Sweden to culture and historical events, the two peers illuminated milk consumption from perspectives beyond the health aspects that were covered in the public service article.

Economy and Marketing In addition to framing the cultural and historical values of milk in Sweden, the student groups reflected upon how decreased milk consumption would affect the Swedish economy and to what extent the conception of milk as healthy could be a result of marketing. The following episode (Excerpt H) illustrates how Mimmi, Sam, and Tim questioned the way milk has been promoted in Swedish society and schools.

Excerpt H To boost Swedish milk production

62. Tim: I think that the issue about milk consumption is that we have always believed for such a long time that milk is really good. It's hard... our parents... it's hard to tell them that milk isn't nutritious and really great. Or, it's nutritious but...

63. Sam: Yeah, exactly.

64. Tim: If you take a look at the marketing, like, "nature's own sports drink"... that it should be so natural and stuff, but it's really, like, big industry. Maybe it's not that super healthy. 
65. Mimmi: Yeah, the thing is that we've had a milk culture in Sweden. In schools and everything they still promote milk, like, "you should drink it because then you get strong bones."

66. Mimmi: The article shows that we are actually fine without milk and you can see that just by looking outside the borders of Sweden.

67. Tim: Sweden has had such a milk culture for so long that if we changed and very strongly promoted the oat drink it could give, like... We have to find new ways for farmers to produce.

68. Mimmi: This milk culture has to do with that people... they want to be able to boost the Swedish milk production. Like the industry itself. That it should be beneficial for Sweden.

Like Elin and Vera in the previous Excerpt G, Tim expressed a cultural-historical understanding of the high milk consumption in Sweden by referring to older Swedish generations' strong belief in milk as healthy (62). He emphasized the word "believed" in a way that insinuated an assumed lack of scientific evidence behind the suggested health benefits of drinking milk. However, as he then added, "it's nutritious but...", he expressed somewhat contradictory conclusions about the health properties of milk. The ambivalent attitude to milk suggests that reading the public service article made Tim doubt what he already knew about the correlation between milk consumption and health. When his peer Sam agreed (63), Tim then reflected upon what may have caused his previous conception of milk as healthy (64). Drawing on a slogan from a Swedish advertising campaign that branded milk as "nature's own sports drink" (a commercial slogan used by Arla Foods - the largest milk production company in Sweden), Tim connected the notion of milk as "natural" and healthy to the economic interests of milk producers in selling milk (64). When Mimmi added that milk, as part of Swedish food culture, is also promoted in Swedish schools, she questioned the trustworthiness of education (65) in ways that align with how the students in theme 2 scrutinized the objectivity of public service media (c.f. Excerpt E, line 43). Mimmi underscored her statement about milk being branded as healthy by pointing out that the high milk consumption in Sweden could not be justified or explained in terms of health benefits, since milk consumption is significantly lower in other parts of the world- "we are actually fine without milk" (66). Tim validated Mimmi' s conclusions about Swedish milk consumption being commercially reinforced. He suggested that decreased cow's milk consumption in Sweden in favor of oat milk would be more likely to disadvantage Swedish farmers than threaten public health (67).

Agreeing with Mimmi (65), students in several groups expressed the view that milk is "promoted" in Swedish schools; for instance, since it is served in the lunch canteens. Anna, a student from another group, stated that "[s]omething in me says, like, that I just want milk to be, like, as good as I've always believed it to be or, like, learnt when I was a kid." Similarly, Anna related her sense of trust in milk as a healthy beverage to early childhood education and voiced an unwillingness, yet potential necessity, for re-evaluating what she thought she knew.

\subsection{Themes of Meaning-Students' Enactments of "an Examined Life"}

Drawing on the framework of "an examined life" (Nussbaum 1997), two themes of meaning were discerned in students' engagement with the alarming findings on milk. The framework of "an examined life" enabled an understanding of the students' critical examination of the alarming findings on milk as a way to question various authorities in society and to reflect upon the roles and values of milk from multiple perspectives. Thus, complementary to the descriptive themes, the themes of meaning illuminate qualities in the students' critical examination that go beyond their scrutiny of specific areas of content. 


\subsubsection{A) Questioning Authorities}

Nussbaum (1997 p. 62) writes that the capacity to critically examine contemporary issues evolves as students "gradually take on the ability to distinguish, within their own traditions, what is parochial from what is commended as a norm for others, what is arbitrary and unjustified from that which may be justified by reasoned argument." Thus, living "an examined life" implies that young people "search for arguments to justify their beliefs rather than simply following parents and civic authorities" (p. 15). Aligning with such a view, a theme of meaning that runs across all descriptive themes relates to how the contradictory media message created a space for the students to identify and question authorities - in their own lives and in Swedish society at large. There are multiple examples of how students' encounters with the alarming findings on milk sparked their examination of what had shaped their own habits, opinions, and knowledge about milk. In effect, the students' critical examination of the new findings encompassed not only inquiring what they knew about milk but also why they had perceived milk as "healthy" and "natural." During their conversations, the student groups identified the existence of a "Swedish milk culture." Maintained by family traditions, education, and the dairy industry itself, a conception of milk as particularly healthy, bone-strengthening, and "natural" had been passed down from generation to generation in Swedish society. The students' recognition of a "Swedish milk culture" is, for instance, illustrated in the conversation between Tim and his peers (62-68). Together, they pointed to the difficulties of introducing the new findings on milk to Swedish society. The challenges relate to the tendency of parents, schools, and marketing campaigns to brand milk as "nature's own sports drink."

Recognizing milk as a culturally laden and big-industry product allowed the students to further probe which authorities may have contributed to constructing the image of milk as healthy and on what grounds they did so. The concept of "an examined life" allows one to recognize the special role in influencing people's lives that the written word plays among all authorities in past and contemporary societies. Encouraging students to become "passively reliant on the written word" constrains them from "search[ing] themselves, looking for arguments for and against their culture's ways of doing things" (Nussbaum 1997 p. 34). Recall that the nutrition study was conducted by a team of researchers at a highly regarded university in Sweden, published in an international peer-review academic journal, and reported by a science journalist in public service news media. However, rather than uncritically accepting what was stated in the article, the students were spurred to question how scientific advancements are produced in science communities and further communicated in news media. Nussbaum (1997 p. 39) argues that "one of the factors to be considered in evaluating a claim is the role of social and political power in shaping the concepts it contains." Rather than deciding whether the scientific claims about milk were "true or false," the students' inquired how the new findings had been produced, validated, and explained. They demonstrated an awareness that research findings are constructed within communities of science and therefore important to examine in relation to the accumulated knowledge in the field. By comparing the results of the nutrition study with competing scientific knowledge regarding milk and health, Sam and his peers expressed an understanding of scientific research as a contingent process of knowledge building rather than as a production of "true facts" (35-42).

While engaged in such work, the students identified and used a range of established quality markers commonly applied to evaluate epidemiological correlation studies, such as the doseresponse relationship and the physiological mechanism. The students' capabilities to critically 
examine the authority of science communities were conditioned by how they interpreted the methodological information and quantitative data about the nutrition study presented in the public service article. The information provided in the public service article was technical and the students struggled to understand and explain the alarming correlation between milk consumption and health risks. Instead, they drew on their previous knowledge about the nutrient components in milk (e.g., it contains calcium and lactose) to elaborate on plausible physiological mechanisms behind the controversial findings (29-34). Opportunities to make sense of the information emerged as the students related it to situations and measures that they were familiar with, such as comparing the doses of milk stated in the article to how milk is generally consumed and quantified in society, like "a glass per day" (24) or "if you drink milk with every meal" (25).

In addition to questioning the authority of science communities, the students acknowledged nonprofit public service news media reporting as a political and social practice. While engaged in such work, they identified and discussed established quality markers for source critique, such as the importance of media in reflecting both sides of an issue $(46,47,49)$, being transparent about primary sources $(51,53)$, and being free from economic interests (48). The students demonstrated the capabilities to discern limitations in strictly following predefined questions or quality markers to evaluate trustworthiness. Across the groups, the students articulated the view that merely having sources reflecting multiple perspectives of an issue does not ensure that the information provided is to be regarded objective and free from human values. This was illustrated, for instance, when Sara and Tim suggested that public service media may have contributed to shaping the Swedish conception of cow's milk as a healthy beverage $(43,45)$ or when Malte distinguished between the interests or purposes of news media and the interests or purposes of the people that they quote or interview $(50,54)$.

\subsubsection{B) Acknowledging Multiple Perspectives}

In a complex world, issues of concern need to be examined from a plurality of perspectives (Nussbaum 1997) Living "an examined life" implies that students become "critical about their habits and conventions; and such critical inquiry, in turn, requires awareness that life contains other possibilities" (op. cit. p. 54). Opportunities to practice "an examined life" arise as students are confronted "with difference in an area where they had previously thought their own ways neutral, necessary, and natural" (op. cit. p. 32). A theme of meaning in students' inquiry into the alarming findings concerns how they reflected upon the roles and values of milk from multiple perspectives. Even though the public service article focused on milk consumption from a strictly nutritional standpoint, the students demonstrated a capacity to inquire into the new findings from a broader perspective.

As illustrated in the previous section, the students expanded the notion of milk consumption as mere "nutrition" by recognizing it's cultural, historical, and economic value in Sweden. In doing so, they recognized various stakeholders' dependency on (or interest in) the consumption and production of milk and probed what consequences decreased milk consumption would have - for them as individuals, as well as for Swedish society generally. During related episodes, the students attributed emotional values to milk from both societal and personal standpoints. Elin, for instance, expressed a personal preference for milk and shared her worries that any recommendation to decrease milk consumption would stir up strong emotions in Sweden (60). Tim and Mimmi pointed out that decreased milk consumption would potentially affect Swedish farmers negatively $(67,68)$. Similarly, the students inquired into the 
consequences of decreased milk consumption - not only with regard to their individual health but in relation to how it could affect other people.

There are also examples of how the students contrasted their own views about milk with how milk is consumed around the world. Mimmi, for instance, stated that "we are actually fine without milk and you can see that just by looking outside the borders of Sweden" (66). By reflecting on Swedish attitudes to milk, the students also expressed awareness that food cultures vary and that some people use dairy products differently or exclude them from their diet entirely. Both Vera and Elin pointed out that food choices in our home kitchens can be seen as part of the cultural-historical making of Swedes and therefore difficult to change regardless of scientific findings suggesting otherwise $(60,61)$. Thus, illuminating the new findings from multiple perspectives enabled the students to contrast their own lifestyle with alternative ways of living and, by extension, to understand other cultures, to recognize the needs of others, and thereby to understand themselves.

\section{Discussion and Conclusions}

In this paper, we have reported on how upper secondary school students engaged in critical examination of alarming findings on milk consumption and health accessed through Swedish public service news media on the Internet. The controversial media message about milk created an opportunity for the students to critically examine the alarming findings with regard to how science is produced and explained, how science is communicated in media, and the possible consequences of new scientific knowledge. Despite the recognized difficulties for people without specialist competences to scrutinize and make meaning of science in media (c.f. Lee et al. 2017; Nagler 2014; Gillen 2006), the student groups examined the alarming findings on milk using similar methods to those used to scrutinize research in science communities. They demonstrated the capabilities to address details and technicalities regarding how the nutrition study had been designed and carried out and how the results had been interpreted by the researchers. The framework of "an examined life" (Nussbaum 1997) opens up to recognize the questioning and scrutiny of authorities in society, which is an important aspect of critical examination. In this study, the students examined the social practices and institutions that had produced, interpreted, and communicated the findings on milk (such as a university and public service media). The students' engagement in this task was conditioned by their willingness and capabilities to address questions of epistemology, including how scientific knowledge is produced in communities of science and the extent to which media reporting about science could (or should) be "objective." This suggests that the critical examination of science in media reaches beyond trusting the "right" sources. We have previously shown (Wiblom et al. 2017) that predefining certain sources, like universities and government, as trustworthy per se, may allow students to shortcut their evaluation of sources found on the Internet. The present study provides insights into how encounters with controversial science in media may also facilitate students' scrutiny of sources commonly regarded as "legit"-in science education and in society at large. This gives support to Priest's (2013 p. 139) suggestion that knowledge about "how science works" and, furthermore, how news media is constructed may afford nonscientists the opportunity to critically examine technical scientific claims reported in the media.

As the students probed plausible consequences of the alarming findings on milk from multiple perspectives, their engagement with emerging science reached beyond clarifying what is "true" and what is "false." Taking different perspectives into account allows students to map and sort out the complexity that typically surrounds science-related controversies and furthermore to distance 
themselves from the stakes of others (Solli et al. 2017). In our view, the concept "an examined life" enables one to discern and articulate qualities in student conversations that relate to how students examined, rather than distanced themselves from meeting difference. The controversial media message depicting milk consumption as unhealthy functioned as an incentive for the students to question the foundations of their own conceptions of milk in ways which aligned with the notion of Socratic inquiry as examining what is already known. Nussbaum (1997 p. 36) argues that opportunities to practice "an examined life" arise as students are invited to "[s]ort out what they think they know, to test beliefs for consistency, inferences for validit[y]". Contrasting their own traditions and preferences around milk with how milk is consumed around the world enabled the students to discern and accept other people's valuing, interest in, or dependency on milk. This suggests that when the issues addressed in science education converge with what is personally relevant to the students, opportunities may be established that afford conversations on the production of scientific knowledge as embedded in social, cultural, and historical practices. Since scientific advancements intervene in society and in people's lives, they ought to be examined and evaluated not only from within communities of science but by the people whose lives are affected by new findings.

In conclusion, the framework of "an examined life" may serve as a useful conceptual tool in framing the qualities of students' critical examination of science that have previously been given less attention in science education and research. In the present study, the concept enabled the understanding of students' critical engagement with the alarming findings to be conditioned by their willingness to question authoritative voices in society and their capabilities to illuminate the new findings from multiple perspectives. Thus, inviting students to critically examine controversial science in media may open up spaces for addressing questions of epistemology in science education, such as an inquiry into the conditions under which a scientific claim is produced and communicated. Students' engagement in related activities shows promise for enabling a critical examination of themselves and others in ways deemed important for democratic citizenship. Learning to respond critically to emerging science in the media requires the students to develop skills other than mere familiarity with scientific concepts and facts. If anything, it is the lack of established knowledge that characterizes the science accessible to lay people through contemporary media (Bradford 2013). It is sometimes argued that science journalists should do better to convey a more representative picture of related fields of knowledge and assist lay people to sort out contradictory claims (Priest 2013). This study provides an example of that even when the controversial findings are produced by a reputed university and are communicated through independent media; upper secondary students are capable of discerning the need to scrutinize such findings and are furthermore capable of performing such critical examination with scientific methods. However, we acknowledge there is a need for future research on how to design classroom activities that invite students to develop capabilities for examination of science particularly relating to issues of one's cultural identity and habits of life.

\section{Compliance with Ethical Standards}

Conflict of Interest The authors declare that they have no conflict of interest.

Funding Information Open access funding provided by Stockholm University. We would also like to include that funding is provided by the Swedish National Agency of Education (reference number 2015:01381).

Open Access This article is licensed under a Creative Commons Attribution 4.0 International License, which permits use, sharing, adaptation, distribution and reproduction in any medium or format, as long as you give appropriate credit to the original author(s) and the source, provide a link to the Creative Commons licence, and indicate if changes were made. The images or other third party material in this article are included in the article's 
Creative Commons licence, unless indicated otherwise in a credit line to the material. If material is not included in the article's Creative Commons licence and your intended use is not permitted by statutory regulation or exceeds the permitted use, you will need to obtain permission directly from the copyright holder. To view a copy of this licence, visit http://creativecommons.org/licenses/by/4.0/.

\section{References}

Andreé, M., \& Lundegård, I. (2013). Scientific literacy som argumentation och kritik. In E. Lundqvist, R. Säljö, \& L. Östman (Eds.), Scientific Literacy. Teori och Praktik. Malmö: Gleerups.

Belova, N., \& Eilks, I. (2016). German teachers' views on promoting scientific media literacy using advertising in the science classroom. International Journal of Science Education \& Mathematics, 14(7), 1233-1254.

Berzonsky, A. W., \& Richardson, D. K. (2008). Referencing science: Teaching undergraduates to identify, validate, and utilize peer-reviewed online literature. Journal of Natural Resources \& Life Sciences Education, 37, 8-13.

Bradford, L. Y. (2013). Media literacy: a health education perspective. Journal of Health Education, 30(3), 180184.

Buckingham, D. (2003). Media education: literacy, learning and contemporary culture. Cambridge: Polity Press.

Chang Rundgren, S. N. \& Rundgren, C-J (2014). SSI pedagogic discourse: embracing scientific media literacy and ESD to face the multimedia world. In: Science education research and Education for sustainable development: a collection of invited papers inspired by the 22nd Symposium on Chemistry and Science Education held at the University of Bremen, 19-21 June 2014.

Choi, M., Glassman, M., \& Cristol, D. (2017). What it means to be a citizen in the internet age: Development of a reliable and valid digital citizenship scale. Computers \& Education, 107, 100-112.

Cockerill, M. P. (2014). Beyond education for economic poductivity alone: the capabilities approach. International Journal of Educational Research, 66, 13.21.

DeBoer, G. E. (2000). Scientific literacy: another look at its historical and contemporary meanings and its relationship to science education reform. Journal of Research in Science Teaching, 37(6), 582-601.

Dede, C. (2010). Comparing frameworks for 21 st century skills. In J. Bellance \& R. Brandt (Eds.), 21st century skills: Rethinking how students learn (pp. 51-76). Bloomington: Solution Tree Press.

Eilks, I., Nielsen, J. A., \& Hofstein, A. (2014). Learning about the role of science in public debate as an essential component of scientific literacy. In A. Tiberghien, C. Bruguière, \& P. Clément (Eds.), Topics and trends in current science education (pp. 85-100). Dordrecht: Springer.

Flaxman, S., Goel, S., \& Rao, J. (2016). Filter bubbles, echo chambers, and online news consumption. Public Opinion Quarterly, 80, 298.

Gillen, M. C. (2006). Criticism and interpretation: teaching the persuasive aspects of research articles. CBE Life Sciences Education, 5, 34-38.

Goldberg, J. P., \& Silwa, S. A. (2011). Communicating actionable nutrition messages: challenges and opportunities. Proceedings of the Nutrition Society, 70(1), 26-37.

Graneheim, U. H., \& Lundman, B. (2003). Qualitative content analysis in nursing research: concepts, procedures and measures to achieve trustworthiness. Nurse Education Today, 24, 105-112.

Graneheim, U. H., Lindgren, B. M. \& Lundman, B. (2017). Methodological challenges in qualitative content analysis: a discussion paper. Nurse Education Today, 56, 29-34.

Hodson, D. (2011). Looking to the future. Rotterdam: Sense Publishers.

Jönsson, H. (2005). Mjölk - en kulturanalys av mejeridiskens nya ekonomi. Brutus Östlings Bokförlag Symposia.

Kininmonth, A. R., Jamil, N., Almatrouk, N., \& Evans, C. (2017). Quality assessment of nutrition coverage in the media: a 6-week survey of five popular UK newspapers. BMJ Open, 7(12), e014633.

Klosterman, M. L., Sadler, T. D., \& Brown, J. (2012). Science teachers' use of mass media to address socioscientific and sustain capabilities issues. Research in Science Education, 42, 51-74.

Laugksch, R. C. (2000). Scientific literacy: a conceptual overview. Science Education, 84(1), 71-94.

Lee, K., Hoti, K., Hughes, J. D., \& Memmerton, L. M. (2014). Dr Google and the consumer: a qualitative study exploring the navigational needs and online health information-seeking behaviours of consumers with chronic health conditions. Journal of Medical Internet Research, 16(12), 262.

Lee, C. J., Nagler, R. H., \& Wang, N. (2017). Source-specific exposure to contradictory nutrition information: documenting prevalence and effects on adverse cognitive and behavioral outcomes. Health Communication, 33(4), 453-461.

Mason, L., Scrimin, S., Tornatora, M. C., Suitner, C., \& Moè, A. (2018). Internet source evaluation: the role of implicit associations and psychophysiological self-regulation. Computers \& Education, 119, 59-75. 
McClune, B., \& Jarman, R. (2010). Developing students' capabilities to engage critically with science in the news: identifying elements of the "media awareness" dimension. Curriculum Journal, 21(1), 47-64.

McClune, B., \& Jarman, M. (2012). Encouraging and equipping students to engage critically with science in the news: what can we learn from the literature? Studies in Science Education, 48(1), 1-49.

McClune, B., \& Jarman, M. (2014). Promoting science literacy via science journalism: issues and challenges. In L. T. W. Hin \& R. Subramaniam (Eds.), Communicating Science to the Public. Opportunities and Challenges for the Asia-Pacific Region. Netherlands: Springer.

McKenney, S., \& Reeves, T. C. (2012). Conducting educational design research. London: Routledge.

Michaëlsson, K., Wolk, A., Langenskiöld, S., Basu, S., Warensjö Lemming, E., Melhus, H., \& Byberg, L. (2014). Milk intake and risk of mortality and fractures in women and men: cohort studies. British Medical Journal, 239.

Mjölkpropagandan (1933-1964) Tidsskrift för näringshygien, mjölkhushållning och jordbruk. Stockholm: Mjölkpropagandan.

Nagler, R. H. (2014). Adverse outcomes associated with media exposure to contradictory nutrition messages. Journal of Health Communication, 19(1), 24-40.

Nielsen, J. A. (2013). Delusions about evidence: on why scientific evidence should not be the main concern in socioscientific decision making. Canadian Journal of Science, Mathematics, and Technology Education, 13(4), 373-385.

Nussbaum, M. C. (1997). Cultivating humanity. a classical defense of reform in liberal education. Cambridge: Harvard University Press.

Nussbaum, M. C. (2011). Creating capabilities: the human development approach. Cambridge: Harvard University Press.

Organisation For Economic Co-Operation and Development [OECD] (2005) The definition and selection of key competencies [executive summary]. Available online at: http://www.oecd.org/dataoecd/47/61/35070367.pdf.

Priest, S. (2013). Critical science literacy. What citizens and journalists need to know to make sense of science. Bulletin of Science, Technology \& Society, 33(5-6), 138-145.

Priest S. (2016) Communicating Climate Change. The path forward. Palgrave Studies in Media and Environmental Communication. London: Palgrave Macmillan.

Rundgren, C.-J., Chang Rundgren, S.-N., Tseng, Y. H., Lin, P.-L., \& Chang, C.-Y. (2012). Are you SLiM? Developing an instrument for civic scientific literacy measurement (SLiM) based on media coverage. Public Understanding of Science, 21(6), 759-773.

Sjöström, J., Frerichs, N., Zuin, V.G. \& Eilks, I. (2017) Use of the concept of Bildung in the international science education literature, its potential, and implications for teaching and learning. Studies in Science Education 53 (2), 165-192.

Solli, A., Hillman, T., \& Mäkitalo, Å. (2017). Navigating the complexity of socioscientific controversies- how students make multiple voices present in discourse. Research in Science Education. https://doi.org/10.1007 /s11165-017-9668-5.

Solli, A., Hillman, T., \& Mäkitalo, Å. (2018). Rendering controversial socioscientific issues legible through digital mapping tools. International Journal of Computer-Supported Collaborative Learning. https://oi. org/10.1007/s11412-018-9286-x.

Stuckey, M., Heering, P., Mamlok-Naaman, R., Hofstein, A., \& Eilks, I. (2015). The philosophical works of Ludwik fleck and their potential meaning for teaching and learning science. Science \& Education, 24(3), 281-298.

Su, Y. F.-L., Akin, H., Brossard, D., Scheuefele, A. D., \& Xenos, A. M. (2015). Science news consumption patterns and their implications for public understanding of science. Journalism and Mass Communication Quaterly, 92(3), 597-616.

SVT (2014-06-23) https://www.svt.se/nyheter/vetenskap/uppsala-forskare-mjolkdrickande-kopplat-till-okaddodlighet.

The Swedish Agriculture Department (2018). Marknadsrapport mjölk och mejeriprodukter. Utveckling till och med 2018. Retrieved 2018-05-14 from: http://www.jordbruksverket.se/download/18.114 a33071628876461090a02/1522929812136/Marknadsrapport\%20mejeri\%202018.pdf.

The Swedish Media Council (2019). Ungar \& Medier 2019 [Youths \& Media 2019]. Retrieved 2019-09-17 from: https://statensmedierad.se/download/18.126747f416d00e1ba946903a/1568041620554/Ungar\%20 och\%20medier\%202019\%20tillganglighetsanpassad.pdf.

The Swedish National Agency for Education (2011). Science Studies curriculum. Retrieved 2018-07-17 from: https://skolverket.se.

United Nations (2015). Transforming our world: the 2030 agenda for sustainable development. Retrieved 201909-17 from: https://sustainabledevelopment.un.org/content/documents/21252030\%20Agenda\%20for\%20 Sustainable\%20Development\%20web.pdf.

Weinstein, M. (2009). Critical science literacy: identifying inscription in lives of resistance. Journal for Activist Science and Technology Education, 1(2), 2-11. 
Wiblom, J., Rundgren, C-J. \& Andrée, M. (2017). Developing students critical reasoning about online health Information: A Capabilities Approach. Research in Science Education. DOI : https://doi.org/10.1007 /s11165-017-9674-7.

Publisher's Note Springer Nature remains neutral with regard to jurisdictional claims in published maps and institutional affiliations.

\section{Affiliations}

\section{Jonna Wiblom $^{1} \cdot$ Maria Andrée $^{1} \cdot$ Carl-Johan Rundgren $^{1}$}

1 Department of Mathematics and Science Education, Stockholm University, SE-106 91 Stockholm, Sweden 